Çukurova Üniversitesi Mühendislik Mimarlık Fakültesi Dergisi, 32(1), ss. 89-97, Mart 2017

Çukurova University Journal of the Faculty of Engineering and Architecture, 32(1), pp. 89-97, March 2017

\title{
Baraj Rezervuarlarına Sediment Etkisinin Araştırılması: Berdan Barajı Örneği
}

\author{
Şerife Pınar GÜVEL ${ }^{* 1}$, Bülent SELEK ${ }^{2}$, Galip SEÇKİN ${ }^{3}$ \\ ${ }^{1}$ DSI Genel Müdürlüğü, 6. Bölge Müdürlüğü, Adana \\ ${ }^{2}$ DSI Genel Müdürlü̆̆̈̈, Etüt, Planlama ve Tahsisler Dairesi Başkanlı̆̆l, Ankara \\ ${ }^{3}$ Çukurova Üniversitesi, Mühendislik Mimarlık Fakültesi, Çevre Mühendisliği Bölümü, Adana \\ $\ddot{\mathbf{O} z}$ \\ Geliş tarihi: 04.01.2017 Kabul tarihi: 14.01.2017
}

Baraj projelerinin planlanmasında sediment ölçümleri, ölü hacmin güvenilir olarak hesaplanması için kullanılmaktadır. Mühendislik uygulamalarında, sediment hacminin gerçek değerinden düşük hesaplanması depolama tesislerinde işletme-bakım problemlerine neden olmakta ve barajlardan beklenen fayda sağlanamamakta, gerçek değerinden fazla hesaplanması ise maliyeti artırmaktadır. Nehir havzalarında baraj rezervuarlarına taşınan sediment miktarları barajların depolama kapasitesini azaltmakta, bu nedenle tesisler işletmeye alındıktan sonra rezervuar işletme çalışmalarının sediment etkisine bağlı olarak tekrar değerlendirilmesini gerekli duruma getirmektedir.

Berdan Barajı, Türkiye'nin güneyinde Mersin İli'nde, Tarsus İlçesi'nin 6 km kuzeydoğusunda yer almaktadır ve sulama, içme suyu, taşkın kontrolü ve enerji amaçları için Berdan Nehri üzerinde inşa edilmiştir. Berdan Barajı 1984 yılında inşaatı tamamlanarak işletmeye açılmıştır.

Bu çalışmanın amacı, su kaynaklarının planlanması ve yönetimi faaliyetlerinde değerlendirilmek üzere Berdan Barajı rezervuarında biriken sediment miktarının Coğrafi Bilgi Sistemi (CBS) kullanılarak tahmin edilmesidir. Bu kapsamda gerçekleştirilen çalışmada, Berdan Barajı rezervuarında sediment birikiminin analizi, 1961 yılına ait rezervuar sahası haritası ile 2003 yılında hazırlanmış olan hidrografik haritanın Coğrafi Bilgi Sistemi teknolojisi kullanılarak karşılaştırılmasıyla gerçekleştirilmiştir. Çalışma sonucunda rezervuar hacminde 2003 yllina kadar minimum su seviyesinde rezervuar kapasitesinde \%32, normal su seviyesinde rezervuar kapasitesinde $\% 12$, maksimum su seviyesinde rezervuar kapasitesinde $\% 4$ oranında azalma olduğu görülmektedir.

Anahtar Kelimeler: Coğrafi bilgi sistemi, Sedimentasyon, Berdan rezervuarı

\section{Investigation of Sedimentation Effects on Dam Reservoirs: Berdan Dam Example}

\begin{abstract}
Sedimentation measurements are used for calculation of dead volume storage capacity of dams at planning stage of dam projects. Calculating the sedimentation volume less than actual capacity causes operation-maintenance problems at water projects at engineering technics, while calculating the
\end{abstract}

"Sorumlu yazar (Corresponding author): Şerife Pınar GÜVEL, spinar.guvel@dsi.gov.tr 
sedimentation volume more than actual capacity increases cost of water projects. Sediment accumulation in reservoirs decreases water storage capacity of dams in river basins, therefore it is essential to evaluate reservoir operation studies with sedimentation effects.

Berdan Dam is located in Mersin City, $6 \mathrm{~km}$ northeast of Tarsus in the southern part of Turkey, and constructed with purposes of irrigation, drinking water supply, flood control and energy on Berdan River. Berdan Dam was constructed in 1984 and it is operational since then.

The aim of this study is to estimate the amount of accumulated sediment in Berdan Reservoir by using Geographic Information Systems (GIS) to evaluate the water resources planning and management activities of Berdan Dam. In this study, analysis of sediment accumulation in Berdan Dam Reservoir is studied comparing the map of reservoir area with the hydrograhic map prepared in the year 2003 by using geographic information system technology. As a result, it is experienced that there is a $32 \%$ reservoir storage volume loss at minimum reservoir operation elevation, $12 \%$ reservoir storage volume loss at normal reservoir operation elevation and $4 \%$ reservoir storage volume loss at maximum reservoir operation elevation before the year 2003 .

Keywords: Geographic information systems, Sedimentation, Berdan reservoir

\section{GİRIŞ}

Sürdürülebilir su kaynaklarının planlanması ve yönetiminin sağlanması çalışmaları kapsamında, projelerin işletmeye alınmasından sonraki süreçte su kaynakları projelerinin hizmet alanlarında teknik izleme ve değerlendirme faaliyetleri devam etmektedir. Su sınırlı bir kaynak olduğu için dünyada suyun etkin kullanımı her gün daha fazla önem kazanmaktadır. Günümüzde mevcut su potansiyelinin sürdürülebilir hale getirilmesi gerekmektedir [1]. Su kaynaklarının yönetiminde akarsular üzerinde planlanan ve inşa edilen mühendislik yapıları sulama, içmesuyu temini, enerji üretimi gibi amaçlarla insanlara hizmet etmektedir. Baraj rezervuarlarının kapasiteleri, etüt çalışmalarının yanısıra baraj inşaatı tamamlanarak işletmeye açıldıktan sonra da gerekli ölçümler yapılarak değerlendirilmektedir.

Sediment birikimi, rezervuar hacminin azalmasina neden olduğundan baraj işletme çalışmalarını etkilemektedir [2]. Rezervuar sedimentasyonunun değerlendirilmesi hakkında daha önceki yıllarda yapılan çalışmalarda da, rezervuar kapasitesinde azalmaya neden olan sedimentasyonla ilgili sorunlar belirtilmektedir [3-6]. $\mathrm{Bu}$ nedenle rezervuar havzalarındaki sediment dağılımının değerlendirilmesi için mühendislik projelerinde planlama aşamalarından işletme aşamalarına kadar gerekli çalışmalar yapılmalıdır [3]. Sediment birikiminin rezervuar kapasitesinin azalmasina neden olması su kaynaklarının yönetiminde büyük bir problem olarak karşımıza çıkmaktadır.

Mühendislik problemlerinin çözümünde CBS tekniklerinin kullanımı, özellikle su ve toprak kaynaklarının planlanması ve yönetimi uygulamalarında, sulama yönetimi ve çeşitli tarımsal faaliyetler, hidroloji uygulamaları, taşkın risk değerlendirmeleri ve sulama projeleri tabansuyu seviye ölçümlerinin izlenmesi ve incelenmesi gibi çalışmalarda günümüzde yaygın olarak kullanılır hale gelmiştir [1,7-10].

\section{2. ÖNCEKİ ÇALIŞMALAR}

Ülkemizde rezervuar sedimentasyonun incelenmesi konusunda çeşitli araştırmalar bulunmaktadır. Demirköprü Barajında rezervuar sedimentasyonunun değerlendirilmesi çalışmasında hem hidrografik haritalar hem de sediment gözlem istasyonu ölçümleri kullanılmış ve sonuç olarak sediment birikiminden dolayı rezervuar toplam depolama hacminin \%33'ünün kaybedildiği görülmüştür [3]. Sille Barajında 1984-2008 yılları arasında 24 yıllık sürede gölün depolama kapasitesinde sediment birikimi 
nedeniyle \%11,6 azalma olduğu tespit edilmiştir [11]. İstanbul'da bulunan Alibey Baraj1 rezervuarında yapılan araştırmada, barajdaki sedimentasyon incelenmiş, sediment miktarının belirlenebilmesi için arazi çalışmaları ve gözlemleri değerlendirilmiştir [6]. Kalkan [12] tarafından yapılan çalışmada, ülkemizde batimetrik haritaların mevcut durumu incelenerek, güncel batimetrik haritaların yapılması ve barajların dolma hızının tespiti konuları değerlendirilmiştir. Bu çalışmada aynı zamanda, Haliç Islah Projesi kapsamında, Haliç Körfezinin üst bölgesine 16 aylık sürede taşınan sediment miktarının yaklaşık $500.000 \mathrm{~m}^{3}$ olarak hesaplandığ 1 ve dip topoğrafyasındaki değişim izlenmeye çalışıldığ 1 da belirtilmektedir. Balıkesir-Çaygören Rezervuarının sedimentasyon durumunun incelenmesi neticesinde, 1970 ile 1983 yılları arasında, barajın ölü hacminin yaklaşık \%62'sinin dolmuş olduğu belirtilmektedir [13].

Dünyada, rezervuar depolama kapasitesinin etkin kullanımı için sediment birikiminin önlenmesi amaciyla geliştirilen uygulamalar ve rezervuarda kapasite kaybının tespit edildiği çeşitli örnekler bulunmaktadır. Özbekistan'da Akdarya Barajı rezervuarında 2003 yılına kadar, rezervuar orijinal depolama hacminde y1llik azalma oranı $\% 0,8$ olarak belirlenmiştir [14]. Hindistan'da Hirakud rezervuarında, uzaktan algılama teknikleri ile gerçekleştirilen çalışmada, 1989 ve 1957 yılları arasında kapasite kaybı \%24,10 olarak tespit edilmiştir [15]. Hindistan'da Bargi Rezervuarında uzaktan algilama teknikleri kullanılarak sediment depolaması değerlendirilmiş, sonuç olarak sedimentasyon oranı 229,03 $\mathrm{m}^{3} \mathrm{~km}^{-2} \mathrm{yll}^{-1}$ olarak bulunmuştur [16]. Etiyopya'da bulunan Angereb Rezervuarı'nda sedimentasyonun neden olduğu yıllık toplam kapasite kaybı 1997-2005, 1997-2007 ve 2005-2007 yılları için sırasıyla $\% 4,02, \% 3,16$ ve $\% 3,03$ olarak hesaplanmıştır [17].

Baraj planlama çalışmalarında ekonomik ömür esas alınarak rezervuara gelen rusubatı hesaplamak üzere rusubat gözlemleri yapılır ve benzer havzalardaki gerçek sonuçlardan yararlanılır. Rezervuarlarda biriken gerçek sediment miktarını izlemek, sediment dağılımını incelemek amacıyla hidrografik haritalar üretilmektedir. Süspanse sediment ölçümleri yatak yükünü kapsamadığı için, yatak yükünün ayrıca tahminini gerektirmektedir. Bu sebeple, hidrografik haritalar baraj havzaları sediment veriminin belirlenmesi için en güvenilir yöntemdir.

İşletmeye açılmış göllerde birikmiş olan sediment durumunu belirlemek, barajlar ve göllerden uzun süre yararlanmak için hidrografik haritalar yapılmaktadır; DSİ tarafindan Türkiye genelinde 120 barajın ve 62 gölün hidrografik haritası hazırlanmıştır [18].

Sediment gözlem istasyonlarından alınan ölçümler ve üretilen hidrografik haritalar rezervuar sediment birikim oranının hesabında, barajların işletme planının belirlenmesinde ve yeni planlama çalışmalarında kullanılmaktadır.

Doğu Akdeniz Havzasında yer alan ve Berdan Projesi kapsamında geliştirilen, işletme aşamasındaki Berdan Barajı, sulama, taşkın kontrolü, enerji ve Mersin İli’ne içme suyu temini amaçlıdır. Baraj tipi zonlu toprak dolgu, barajın sulama sahası 24.940 ha, rezervuar normal su seviyesi 56,0 m'dir. Berdan Baraj1, Berdan nehri üzerinde inşa edilmiştir. Berdan Nehrinin başlıca kolları Pamukluk ve Kadıncık çaylarıdır.

Proje kapsamında bir baraj ve rezervuar ile bir enerji santrali, sulama ve drenaj sistemleri de bulunmaktadır [19,20]. Planlama çalışmalarında, Berdan Rezervuarında 50 yıllık sürede birikecek rusubat miktarı yaklaşı 16 milyon $\mathrm{m}^{3}$ olarak öngörülmektedir [19]. Berdan Barajı proje karakteristiklerinde, ölü hacim 18 milyon $\mathrm{m}^{3}$ olarak hesaplanmıştır [21].

DSİ tarafindan 2003 yılında Berdan Barajı Rezervuarında hidrografik harita hazırlanmıştır. Bu çalışmada, Berdan Rezervuarında 2003 yılında hazırlanan hidrografik harita ile baraj inşaatı öncesi hazırlanan rezervuar sahası haritasının coğrafi bilgi sistemi ortamında karşılaştırılması ile rezervuar kapasitesindeki gerçek azalma belirlenmiştir ve planlama çalışmasında öngörülen ölü hacim değeri olan 18 milyon $\mathrm{m}^{3}$ değeri ile karşılaştırılmıştır. Çalışmada ek olarak, Berdan 
Barajı Rezervuarında sediment birikiminin coğrafi bilgi sistemi ortamında modellenmesi ile rezervuar aktif hacminde sediment birikimi gerçekleşen alanlar ile rezervuarda sediment dağılımı ve miktarları incelenmiştir.

\section{MATERYAL VE METOT}

\subsection{Materyal}

Çalışmada, Karar Destek Sistemi aracı olarak Coğrafi Bilgi Sistemleri (CBS) teknolojisi kullanılmıştır. Coğrafi bilgi sistemleri ile her ölçekteki veriye ait bilgilerin bilgisayar ortamında depolanması sağlanmakta, bilimsel yöntemlerle gerçekleştirilen modelleme ve analiz çalışmaları ile karar vericilere destek hizmeti sunulmaktadır. CBS tekniği ile depolanan verilerle ve üretilen modellerle, doğal kaynakların yönetiminin yanısıra pek çok bilim dalında çeşitli istatistik değerlendirmeler yapılabilmekte, gelecekteki veri analizi uygulamalarında tarihi verilere kolay ulaşım sağlanmaktadır. Klasik yöntemlerle karşılaştırıldığında, CBS tekniği kullanılarak yapılan planlama çalışmalarında alternatif projeler daha hılı geliştirilebilmektedir. Günümüzde bilimsel araştırmaların yanısıra kurumsal faaliyetler kapsamında da, hem planlama ana done faaliyetlerinde ve planlama raporlarının hazırlanmasında, hem de proje ve inşaat aşaması ile tesislerin işletme çalışmalarında Coğrafi Bilgi Sistemleri kullanılmaktadır. Akarsu havzalarında yeni projelerin geliştirilmesi, çevresel ve tarımsal faaliyetler ve hidrojeoloji konularında da CBS yöntemi başarı ile uygulanmaktadır. Bu çalışmada, Coğrafi Bilgi Sistemi uygulamalarında ArcGIS yazılımı kullanılmıştır.

Araştırmada, sediment birikim haritalarının elde edilmesinde temel altlık olarak, DSİ arşivinde yer alan Berdan Barajı rezervuarına ait 1/5000 ölçekli 1961 yılı haritaları baraj inşaatından önce rezervuar sahasının sayısal yükseklik modelinin oluşturulması ve Berdan Barajı rezervuarına ait 2003 yılına ait hidrografik haritalar, 2003 yılına ait sayısal yükseklik modelinin oluşturulması amacıyla kullanılmıştır. Berdan Barajı rezervuarına ait 1961 yılı haritaları ile 2003 yılı hidrografik haritaları TIFF formatında temin edilmiş, her iki yıla ait haritalar sayısallaştırma işlemi için bilgisayar ortamına koordinatlı olarak aktarılmıştır. Öznitelik veri olarak yükseklik bilgileri kullanılmıştır. Yapılan çalışmada, rezervuar hacmindeki azalma miktarını tespit etmek ve yıllar arasındaki sediment birikiminin dağılımını hesaplamak için, CBS ortamında veri tipleri ve katmanları belirlenerek rezervuar sahası yükseklik verileri sayısallaştırılmıştır. CBS uygulamalarında ArcGIS yazılımında TIN (Triangulated Irregular Network) modülü kullanılarak rezervuara ait sayısal yükseklik modelleri elde edilmiştir. 1961 ve 2003 yılları sayısal yükseklik modelleri ile bulunan her iki yıla ait rezervuar hacimleri incelendiğinde, iki yıl arasında azalarak değișen hacimler arasındaki fark sediment birikimi olarak değerlendirilmektedir.

CBS Analiz yöntemleri kullanılarak, sayısal yükseklik modelleri ile hazırlanan uygulamalarda, rezervuar hacim-kot-alan tabloları elde edilmiş, enkesit ve boykesitler incelenerek rezervuar dip topoğrafyasının değişimi değerlendirilmiş ve CBS teknolojisi kullanılarak rezervuar sahasındaki sediment dağılımı belirlenmiştir.

\subsection{Metod}

Berdan Barajı inşaatından önceki rezervuar sahasına ait sayısal yükseklik modelini elde etmek için yükseklik verilerine bağlı katman tiplerinin belirlenmesiyle bir veritabanı hazırlanmıştır. Rezervuar paftaları, coğrafi bilgi sistemleri ortamında sayısallaştırılma işlemlerinin gerçekleştirilmesi için bilgisayar ortamına koordinatlı olarak aktarılmıştır. Paftalarda yer alan noktasal ve çizgisel verilerle vektör veriler üretilmiş, öznitelik bilgileri mekan bilgileri ile ilişkilendirilerek sisteme aktarılmıştır.

Çalışmada öncelikle 1961 yılı rezervuar sahası haritası ile 2003 yılı hidrografik haritası sayısal hale getirilmiştir. Sayısal haritalardaki noktasal ve çizgisel veriler kullanılarak ve baraj kret kotu ile maksimum su seviyesi dikkate alınarak belirlenen sınır poligonu katmanı kullanılarak, CBS ortamında ArcGIS yazılımında TIN (Triangulated Irregular Network) modülü ile rezervuar sahasına 
ait kot bilgilerine dayalı rezervuar sayısal yükseklik modelleri oluşturulmuştur. CBS tekniği ile modellerin karşılaştırmasını sağlamak için hazırlanan sayısal haritalar Şekil 1 ve Şekil 2'de verilmektedir. Oluşturulan rezervuar sayısal yükseklik modelleri ise Şekil 3 ile Şekil 4'de verilmektedir.

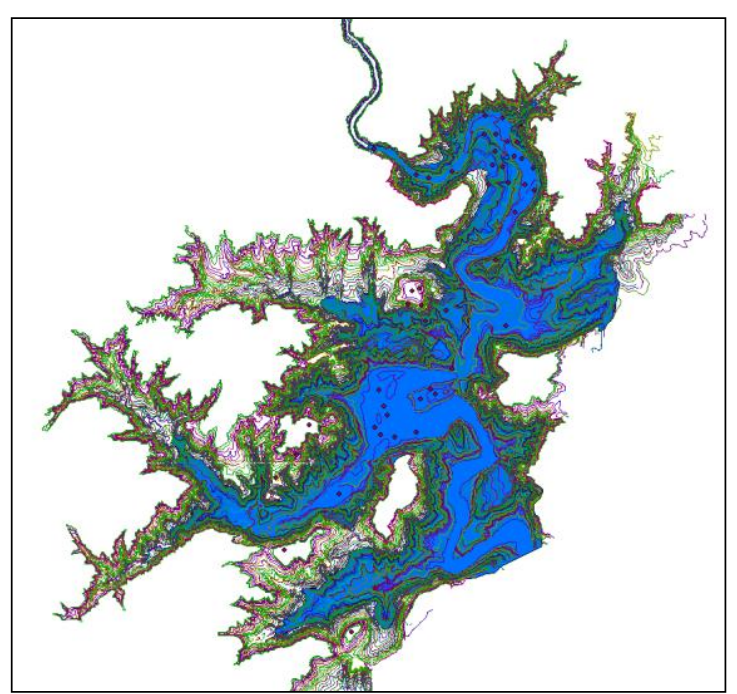

Şekil 1. 1961 yılı için elde edilen rezervuar sahası sayısal haritası

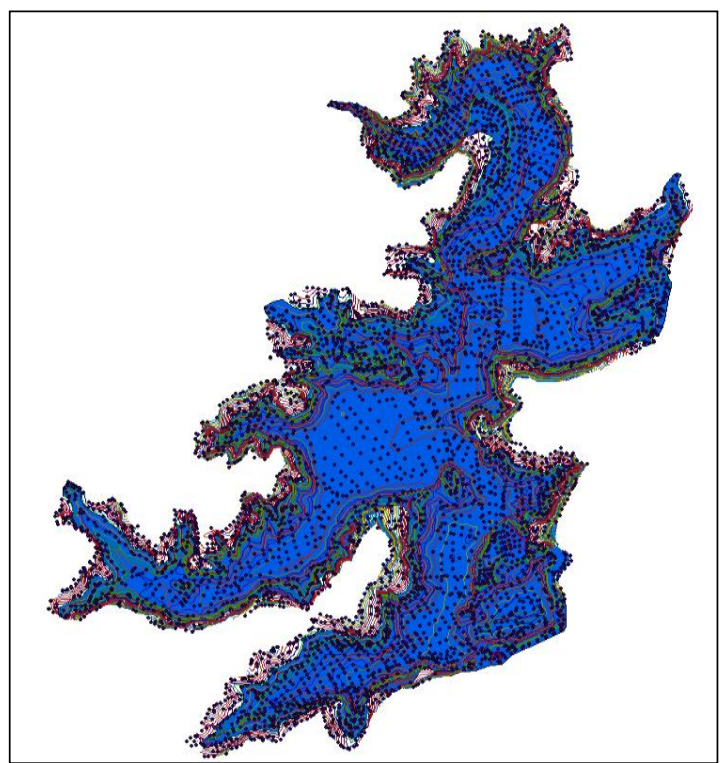

Şekil 2. 2003 yılı için elde edilen rezervuar sahası sayısal haritası
Sayısal yükseklik modelleri ile CBS analiz yöntemleri kullanılarak baraj depolama kapasitesi belirlenmiş, Berdan Barajı Rezervuarında planlama aşamasındaki hacim-kot-alan değerleri ile baraj işletmeye alındıktan sonra 2003 yılında Berdan Barajı Rezervuarında hacim-kot-alan değerleri hesaplanmıştır. Sediment hacim miktarının belirlenmesi için, her iki yıla ait rezervuar hacimlerinin farkı, minimum, normal ve maksimum su seviyelerinde hesaplanmıştır. Berdan rezervuarı hacim-kot eğrileri Şekil 5'de, rezervuar kot-alan eğrileri Şekil 6'da verilmektedir.

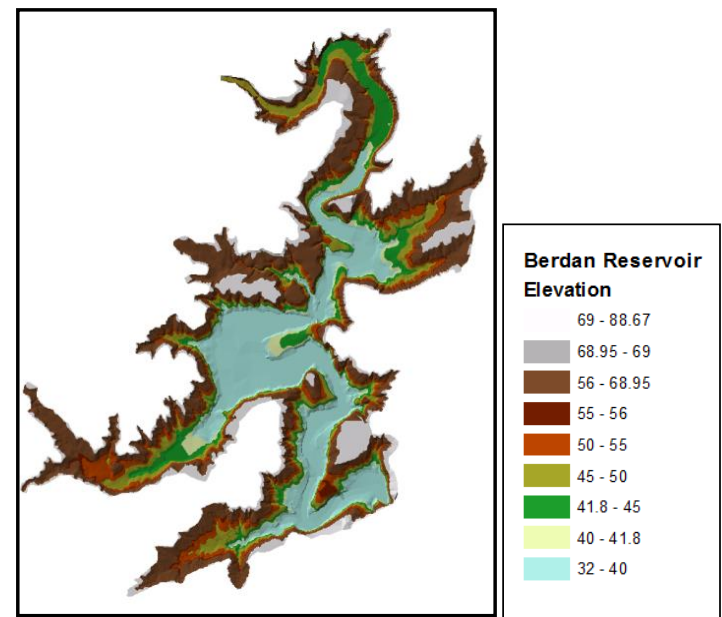

Şekil 3. 1961 yılı için oluşturulan rezervuar sayısal yükseklik modeli

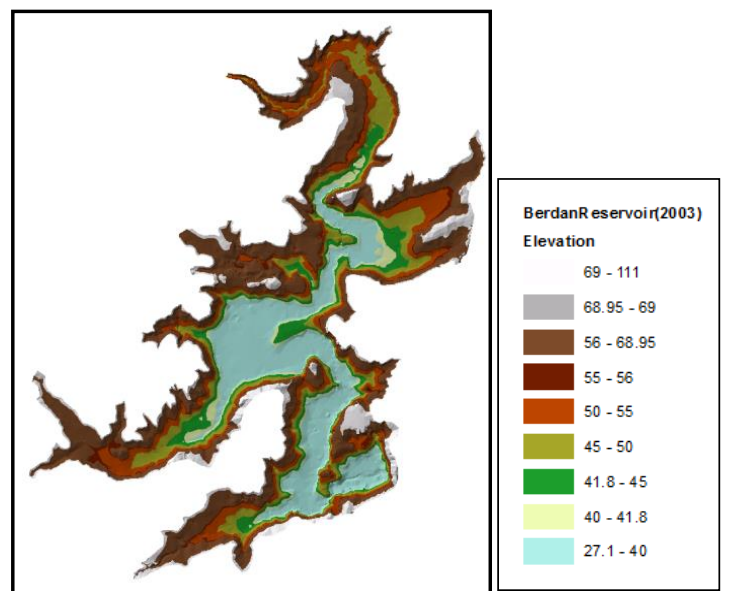

Şekil 4. 2003 yılı için oluşturulan rezervuar sayısal yükseklik modeli 
Şekil 3 ve Şekil 4'de verilen her iki rezervuar sayısal yükseklik modelinde, yüksekliği $40 \mathrm{~m}$ kotuna kadar olan yüzey alanı açık mavi renk ile temsil edilmekte, Şekil 3'de görülen birinci durumdan Şekil 4'de görülen ikinci duruma geçildiğinde, açık mavi renk alanın azaldı̆̆ görülmekte, bu fark sediment birikiminden kaynaklanmaktadır.

Her iki durumda baraj minimum su seviyesi, baraj normal su seviyesi ve baraj maksimum seviyesi oluşturulan lejandda aynı renklerle temsil edilmekte, birinci durumdan ikinci duruma geçildiğinde, sediment birikiminden dolayı olduğu öngörülen, rezervuarda renk dağılımının kotların yükselmesi olması yönünde değişiklik gösterdiği görülmektedir. Ancak kıyıya yakın kesimlerde kotlardaki azalmalar bu kısımlarda erozyon olduğu şeklinde değerlendirilmiştir.

CBS analiz yöntemleri ile hesaplanan ve Berdan Barajı hacim-kot-alan bilgileri ile elde edilen 1961 ve 2003 y1llarına ait rezervuar hacim-kot grafiğinde (Şekil 5), iki yıla ait depolama verileri karşılaştırıldığında rezervuar hacmindeki azalma miktarı görülmektedir. Rezervuarda biriken sediment hacim miktarı, iki yıla ait rezervuar depolama kapasitelerinin farkının hesaplanması ile belirlenmiştir. Şekil 6'da yer alan rezervuar kotalan grafiği incelendiğinde ise, birinci durumdan ikinci duruma geçildiğinde, yaklaşık $55 \mathrm{~m}$ kotlarından sonra alan değerlerinde artma görülmektedir, bu durum kıyı kesimlerine yakın kısımlarda erozyon şeklinde değerlendirilmiştir.

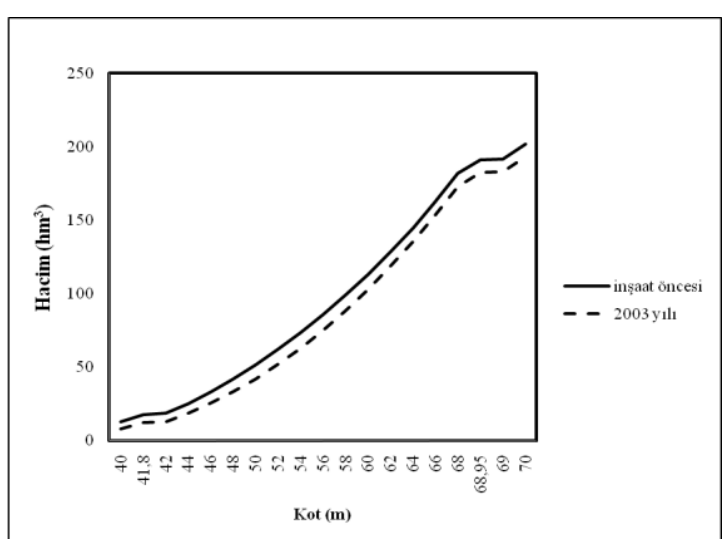

Şekil 5. Rezervuar hacim-kot grafiği

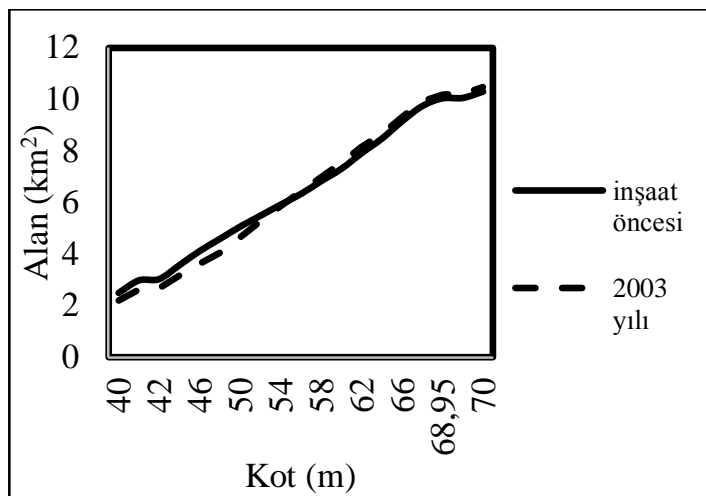

Şekil 6. Rezervuar kot-alan grafiği

Berdan Barajı planlama çalışmalarında, akım rasat verileri ve proje sahası etütleri dikkate alınarak baraj rezervuarına $200 \quad \mathrm{~m}^{3} \mathrm{~km}^{-2} \mathrm{yll}^{-1}$ rusubat taşınacağ 1 kabul edilerek, kabul edilen ekonomik ömür sürecinde, baraj rezervuarına 16 milyon $\mathrm{m}^{3}$ rusubat birikeceği öngörülmüştür [19]. Berdan Barajı'nda sulama yönünden minimum su seviyesi 41,80 m, bu seviyeye karşılık gelen ölü hacim değeri 18 milyon $\mathrm{m}^{3}$ 'tür. Berdan Barajı'nın planlama aşamasındaki rezervuar topoğrafyası ile 2003 yılı hidrografik çalışma sonucu karşılaştırılarak, 2003 yılına kadar minimum su seviyesi olan 41,80 m kotunda 5,73 milyon $\mathrm{m}^{3}$ gerçek sediment birikimi hesaplanmıştır. Sonuç olarak, planlama çalışmalarında öngörülen ölü hacim miktarı 18 milyon $\mathrm{m}^{3}$ iken 2003 yılına kadar 5,73 milyon $\mathrm{m}^{3}$ sediment birikimi gerçekleştiği bu çalışma sonucunda belirlenmiştir.

Berdan Barajı rezervuarında her iki yıl arasındaki sediment birikimini modellemek için sayısal yükseklik modelleri (TIN) öncelikle hücresel raster veri modellere aktarılmıştır. Her iki durum için oluşturulan raster veri modelleri Şekil 7 ve Şekil 8'de verilmiştir. Her iki veri modeli, bilgisayarda aynı anda ekrana çağırılarak CBS ortamında çakıştırılmış ve farklarından oluşan yeni bir veri modeli elde edilmiştir. $\mathrm{Bu}$ yeni veri modeli, Berdan Barajı Rezervuarında sediment dağılımını temsil etmekte, raster veri modelindeki pozitif değerler kot yükselmelerini, dolayısıyla sediment birikimini, negatif değerler ise kotlardaki azalmayı, diğer bir ifadeyle erozyon gerçekleşen alanları göstermektedir. 


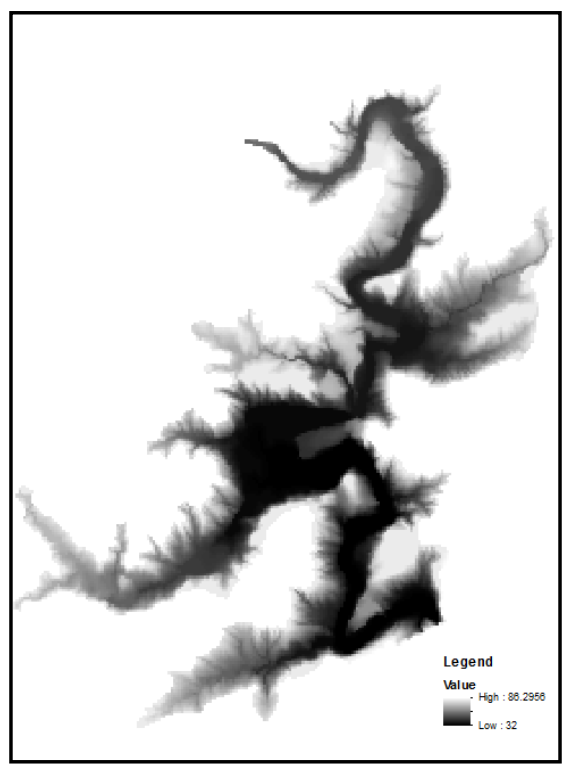

Şekil 7. 1961 yılı için oluşturulan raster veri modeli

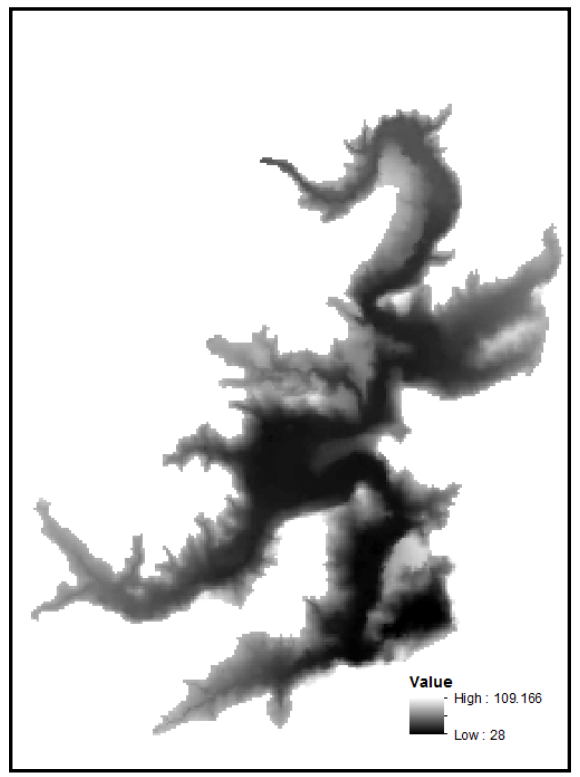

Şekil 8. 2003 y1lı için oluşturulan raster veri modeli

Rezervuar sahasında sediment birikiminden dolayı oluşan değişimler Şekil 9'da gösterilmiştir. CBS analiz sonuçlarına göre, baraj gövdesine yakın kısımlarda, sediment birikim miktarları 1,5 m ile $6 \mathrm{~m}$ arasında değişmektedir. Rezervuar sahasının orta kısımlarında sediment birikimi genel olarak $2 \mathrm{~m}$ ile $6 \mathrm{~m}$ arasında değișmekle birlikte bazı kısımlarda $11 \mathrm{~m}$ ile $13 \mathrm{~m}$ arasında değerlere de ulaşmaktadır. Rezervuarın memba kısmında ise sediment birikimi genel olarak 4 m'ye yakın değerler almakta, bu kısımlarda 6 m'ye kadar sediment birikiminin gerçekleştiği alanlar bulunmaktadır.

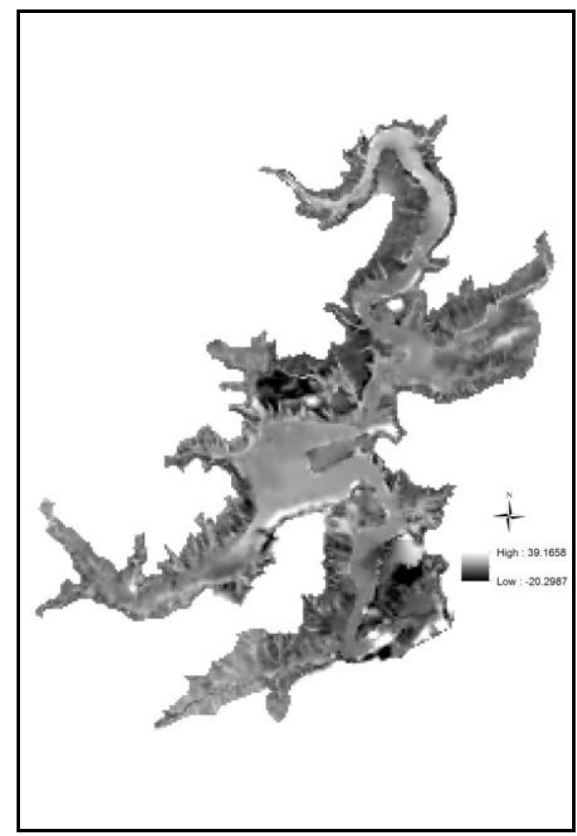

Şekil 9. Berdan barajı rezervuarında sediment birikimi

Rezervuar sahasında meydana gelen değişim, CBS ortamında enkesit ve boykesit örnekleri ile, Şekil 10'da görüldüğü gibi incelenmiştir. Rezervuarda baraj inşaatından önceki durumda ve 2003 yılındaki durumda, rezervuar membası ile baraj aksı arasındaki boyuna profiller incelendiğinde, barajın işletmeye açıldığı 1984 yılından 2003 yılına kadar geçen 19 yıllık sürede, sediment birikiminin gerçekleştiği kısımlar görülmektedir. Ayrıca nehir hattı boyunca sediment birikiminin gerçekleştiği kısımların yanısıra örnek bir enkesitte meydana gelen değişim de görülmektedir. Rezervuar sayısal yükseklik modeli ve CBS katmanları kullanılarak, belirlenen herhangi bir kesitteki yükseklik değişimleri incelenebilmekte, ayrica rezervuar sayısal 
yükseklik modelleri, boykesit ve enkesitlerin elde edilmesi için çeşitli coğrafi sorgulamaların yapılmasına hazır durumda bulunmaktadır.

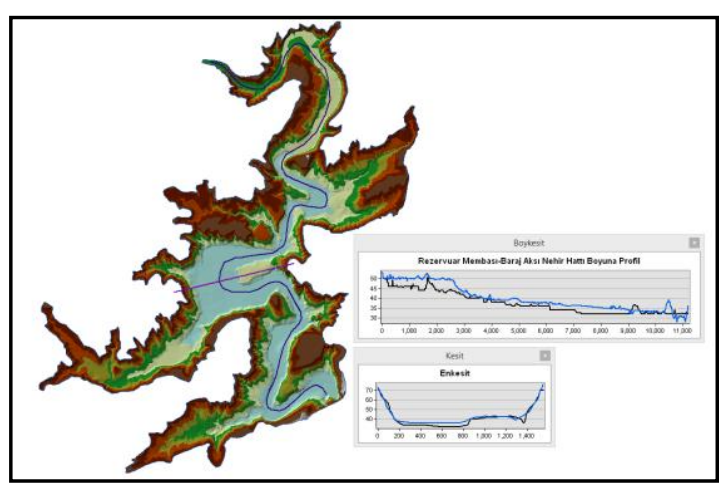

Şekil 10. Rezervuar sahası ve çevresi

\section{SONUÇLAR}

Çalışmada, Berdan Barajı planlama çalışmalarında öngörülen, baraja geleceği tahmin edilen sediment miktarı ile baraj işletmeye açıldıktan sonra fiziki olarak gerçekleşen sediment miktarları coğrafi bilgi sistemleri teknolojisi kullanılarak karşılaştırılmıştır. Planlama kapsamında değerlendirilen hacim-satıh çalışmaları ile 2003 yılına ait baraj hidrografik haritası coğrafi bilgi sistemleri ortamında değerlendirilmiş, rezervuara ait sayısal yükseklik modelleri oluşturularak rezervuar hacmindeki değişimler incelenmiştir.

Rezervuara ait sayısal yükseklik modelleri sediment birikiminin yüksekliklerinin hesaplanması ve sediment dağılımını belirlemek için coğrafi bilgi sistemleri ortamında karşılaştırılmıştır. Rezervuarın enkesit ve boykesitleri modeller üzerinden oluşturularak rezervuar taban yüzeyinde zamanla meydana gelen değişimler incelenmiştir.

$\mathrm{Bu}$ çalışmada hazırlanmış olan coğrafi bilgi sistemleri veritabanı ile, gelecek yıllarda depolama kapasitesinin tekrar değerlendirilmesi için hazırlanacak yeni hidrografik haritalar karşılaştırılarak rezervuar sediment dağılımı güncel hale getirilebilecektir. Ayrica, bu araştırmada hazırlanmış olan sediment dağılım haritas1, rezervuar taban yüzeyinde yeni enkesitlerin elde edilmesinde kullanılabilecektir.

Berdan Barajının su kaynağı olarak teşkil edildiği sulama projelerinin işletme faaliyetlerinin planlanması ve değerlendirilmesinde, bu çalışma sonucunda elde edilen sayısal yüksek modelleri ve sediment birikim haritaları çalışmalara katkı sağlayacaktır.

Berdan Barajında, her iki yıla ait sayısal yükseklik modelleri coğrafi bilgi sistemleri ortamında karşılaştırılmıştır. Sonuç olarak, rezervuar hacminde 2003 yılına kadar minimum su seviyesinde rezervuar kapasitesinde \%32, normal su seviyesinde rezervuar kapasitesinde \%12, maksimum su seviyesinde rezervuar kapasitesinde $\% 4$ oranında azalma olduğu belirlenmiştir. 2003 yılına kadar rezervuar aktif hacmindeki değişimin \%2'ye yaklaşan azalma şeklinde, taşkın hacmindeki değişimin ise $\% 2$ artış şeklinde olduğu belirlenmiştir.

\section{KAYNAKLAR}

1. Gürer, İ., Uçar, İ., 2013. CBS ve Uzaktan Algılama Destekli Kar Erimesi Modeli (SRM) İle Akış Hidrografı Benzetimi (Kayseri-Sarız Çayı Havzası Örneği), Gazi Üniv. Müh. Mim. Fak. Dergisi, Cilt 28, No 1, 91-101.

2. El-Sersawy, H., 2005. Sediment Deposition Mapping In Aswan High Dam Reservoir Using Geographic Information System (GIS), Ninth International Water Technology Conference IWTC9 2005, Sharm El-Sheikh, Egypt.

3. Kokpinar, M. A., Kumcu, S. Y., AltanSakarya, A. B., Gogus, M., 2010. Reservoir Sedimentation in the Demirkopru Dam, Turkey, Proceedings of the International Conference on Fluvial Hydraulics, River Flow 2010, Braunschweig, 2, 1125-1130.

4. Güvel, Ş.P., Yurtal, R., 2007. Karar Destek Sistemi ile Seyhan Baraj Haznesi Katı Madde Birikiminin İncelenmesi, Ç.Ü. Fen Bilimleri Enstitüsü Fen ve Mühendislik Bilimleri Dergisi, Cilt 16, Sayı 1, 134-145.

5. Fakıoglu, M., 2005. Seyhan Barajı Hidrografik Harita Alımı Değerlendirilmesi ve Sonuçları, 2. 
Mühendislik Ölçmeleri Sempozyumu, İstanbul, 23-25 Kasim 2005.

6. Çelik, H. E., Şengönül, K., Akyüz, F., Altunel, O., Dağc1, M., Esin, A.İ., 2012. İstanbul'un İçme Suyu Barajlarının Sedimantasyon Problemi ve Çözüm Önerileri: Alibey Baraj1 Örneği, Istanbul University Journal of Faculty of Forestry, 62, 2, 113-127.

7. Arslan, H., Demir, Y., 2011. Monitoring and Assessing Groundwater level By GIS: A Case Study In The Irrigated Soils of Bafra Plain In Northern Turkey, Anadolu Tarım Bilim Derg., 26, 3, 203-211.

8. Cengiz, T., Akbulak, C., Özcan, H., Baytekin, H., 2013. Gökçeada'da Optimal Arazi Kullanımının Belirlenmesi, Tarım Bilimleri Dergisi, 19, 148-162.

9. Cemek, B., Güler, M., Arslan, H., 2006. Bafra Ovası Sağ Sahil Sulama Alanındaki Tuzluluk Dağılımının Coğrafi Bilgi Sistemleri (CBS) Kullanılarak Belirlenmesi, Atatürk Üniv. Ziraat Fakültesi Derg., 37(1), 63-72, ISSN 1300-9036.

10. Tuğaç, M.G., Torunlar, H., 2007. Tarım Arazilerinin Tarımsal Kullanım Uygunluklarının Belirlenmesi Üzerine Bir Çalışma, Tarım Bilimleri Dergisi, 13 (3), 157-165.

11. Ceylan, A., Yiğit, C. Ö., Ekizoğlu, İ., Özdendinler, A., Bilgin, A., Hisoğlu, Ş., Toprakkale, A., 2009. Barajlarımızdaki Batimetrik Ölçmeler: Sille Barajı Örneği, 4. Ulusal Mühendislik Ölçmeleri Sempozyumu, KTÜ-Trabzon, 14-16 Ekim 2009.

12. Kalkan, Y., 2009. Barajlarımızdaki Hidrografik Ölçmeler ve Sediment Hareketleri, 12. Türkiye Harita Bilimsel ve Teknik Kurultayı, Ankara, 11-15 Mayıs 2009.

13. İrtem, E., Özgür, A. C. A., 2000. BalıkesirÇaygören Rezervuarının Sedimentasyon Açısından İncelenmesi, İMO Teknik Dergi, 2155-2164, Yaz1 150, Kisa Bildiri.

14. Rakhmatullaev, S., Huneau, F., Bakıev, M., Motelica-Heino, M., Le Coustumer, P., 2011. Sedimentation of Reservoirs in Uzbekistan: a Case Study of the Akdarya Reservoir, Zerafshan River Basin, Proceedings of the
ICCE Workshop, Hyderabad, India, IAHS Publ.349.

15. Mukherjee, S., Veer, V., Tyagi, S. K., Sharma, V., 2007. Sedimentation Study of Hirakud Reservoir through Remote Sensing Techniques, Journal of Spatial Hydrology, Vol 7, No 1, 122-130.

16. Goel, M. K., Jain, S. K., Agarwal, P. K., 2002. Assessment of Sediment Deposition Rate in Bargi Reservoir Using Digital Image Processing, Hydrological Sciences-Journal-des Sciences Hydrologiques, Special Issue: Towards Integrated Water Resources Management for Sustainable Development, 47 (S) August 2002.

17. Haregeweyn, N., Melesse, B., Tsunekawa, A., Tsubo, M., Meshesha, D., Balana, B.B., 2012. Reservoir Sedimentation and its Mitigating Strategies: A Case Study of Angereb Reservoir (NW Ethiopia), J Soils Sediments, 12:291-305.

18. Fakığlu, M., Atlıer, Y., 2016. Devlet Su İşleri Genel Müdürlüğünde Hidrografik Harita Çalışmaları, 8. Ulusal Mühendislik Ölçmeleri Sempozyumu, 19-21 Ekim 2016, İstanbul.

19. IECO., 1966. Berdan Geliştirilmesi Teknik ve Ekonomik Fizibilite Raporu Berdan Projesi Mersin İçme Suyu Projesi.

20. IECO, 1966. Su Kaynaklarının Geliştirilmesi Ceyhan Havzası Projeleri, Seyhan Havzası Projeleri, Berdan Projesi, Develi Projesi, Amik Projesi, Master Plan Raporu.

21.DSİ, 1974. Berdan II. Merhale Projesi Planlama Revizyon Raporu, DSİ Genel Müdürlüğü Etüt ve Plan Dairesi Başkanlığı, Temmuz 1974. 
